\title{
Application of satellite images analysis to assess the variability of the surface thermal heat island distribution in urban areas
}

\author{
Janina Fudała $^{l}{ }^{*}$, Ádám Nádudvari ${ }^{l}$, Joachim Bronder $^{l}$ and Marta Fudała ${ }^{l}$ \\ ${ }^{1}$ Institute for Ecology of Industrial Areas, 6 Kossutha St., 40 - 844 Katowice, Poland
}

\begin{abstract}
One of the elements of the urban plans for adapting to climate change is to identify the range the urban heat island (UHI). To a relatively rare ground station network air temperature, one of the possible methods to identify this phenomenon in cities is the analysis of satellite images, and in particular the thermal images surface cities in conjunction with the landuse structure. In the publication is presented the application of indirect methods of determining surface characteristics of heat island in the cities of Upper Silesia Agglomeration on the basis of the analysis of the thermal images from the satellite Landsat for the period 1986-2016. It presents ways to interpret these images depending on the needs of determination the areas sensitive to the impact of the (UHI) and define the areas where adaptation actions to the climate change should be undertaken.
\end{abstract}

\section{Introduction}

The effects of changing climate, particularly increases in temperature, frequency and severity of extreme phenomena occurring in the last few decades, arose. They represent the same threat to the social and economic development of many countries in the world, including Poland. It is therefore necessary to take measures to adapt (adaptation) to the projected impacts of climate change, which should be implemented simultaneously with the activities of limiting greenhouse gas emissions (adaptation).

Observed trends in changes of climatic factors for the period $1981-2015$ for Katowice synoptic station show:

- increase of the maximum temperature,

- increase of the number of days with temperature $>30^{\circ} \mathrm{C}$,

- increase of the number of heat waves during the year,

- increase of the length of heat waves,

- $\quad$ increase of the number of days with temperature $>25^{\circ} \mathrm{C}$ without precipitation.

\footnotetext{
*Corresponding author: j.fudala@ietu.pl
} 
The below Figures 1, 2 and 3 document some of the trends of climatic factors for Katowice synoptic meteorological station, representative for Upper Silesian Agglomeration.

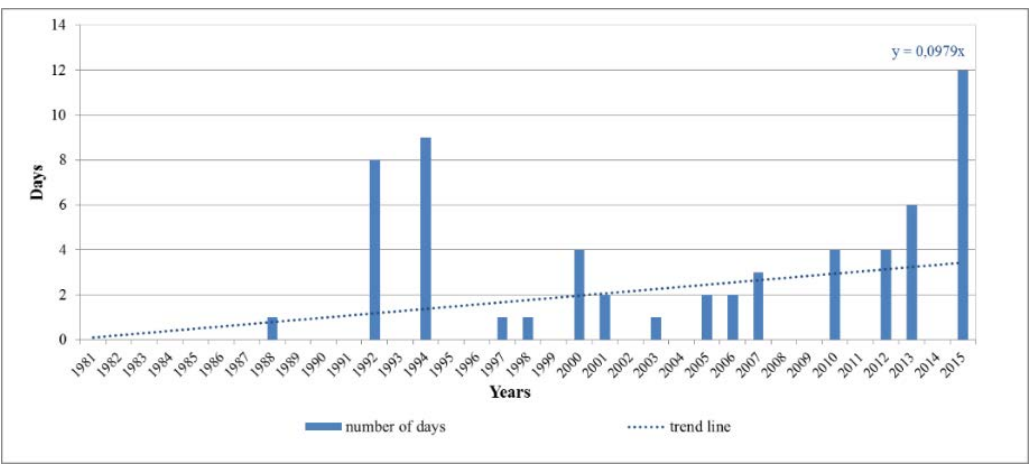

Fig. 1. The number of days with $T_{\max }>98$ th percentile $\left(32.5^{\circ} \mathrm{C}\right)$, Katowice (Poland) synoptic station, 1981-2015; Source: IMGW

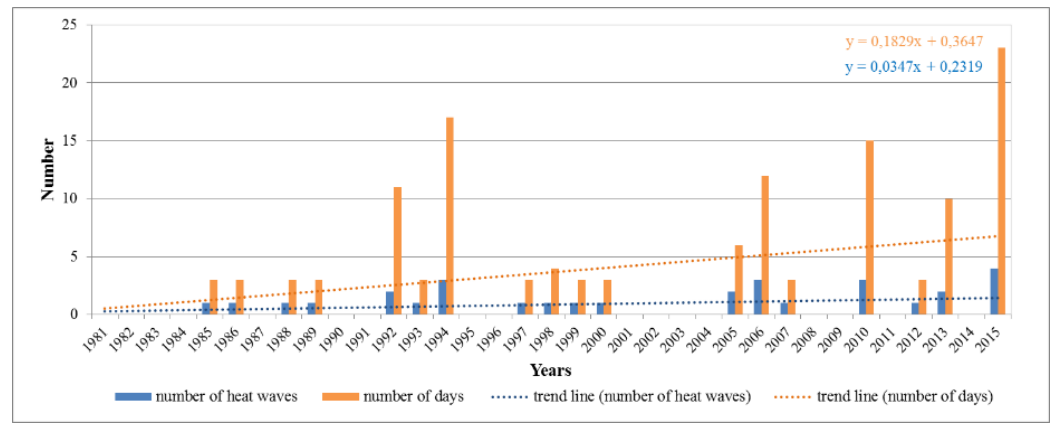

Fig. 2. Heat waves $\left(T_{\max }>30^{\circ} \mathrm{C}\right)$, Katowice (Poland) synoptic station, 1981-2015; Source: IMGW

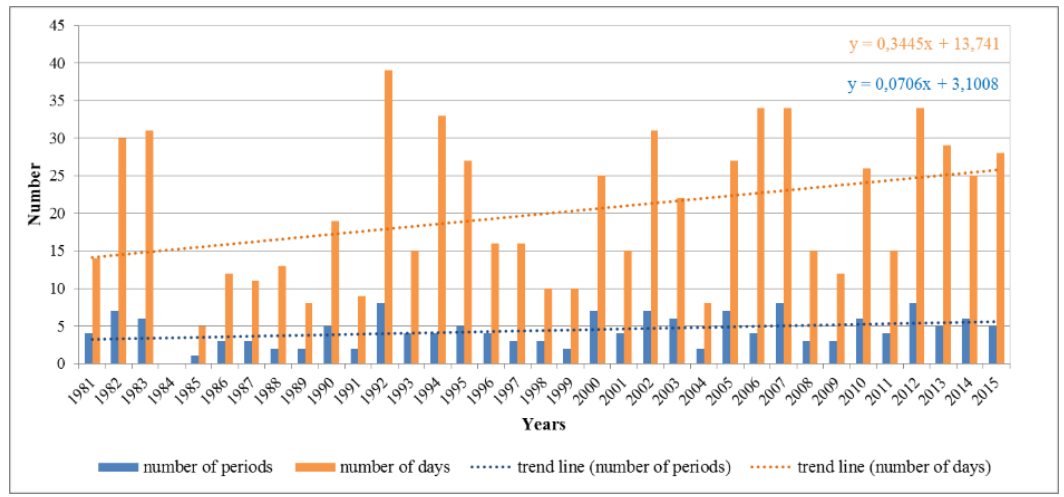

Fig. 3 Precipitation - free days with $T_{\max }>25^{\circ} \mathrm{C}$, Katowice (Poland) synoptic station, 1981-2015; Source: IMGW

It reflects on the severity of the phenomenon of the UHI and the deterioration of the urban quality of life.

The UHI is microclimatological phenomenon, commonly occurring in urban areas, which is characterising the significant increase of the temperature in the town area compared to surrounding areas. It can be compared to the heat island (or sometimes 
archipelago), relative coolness. In the literature and the internet we can find the picture of the UHI as on below Figure 4.

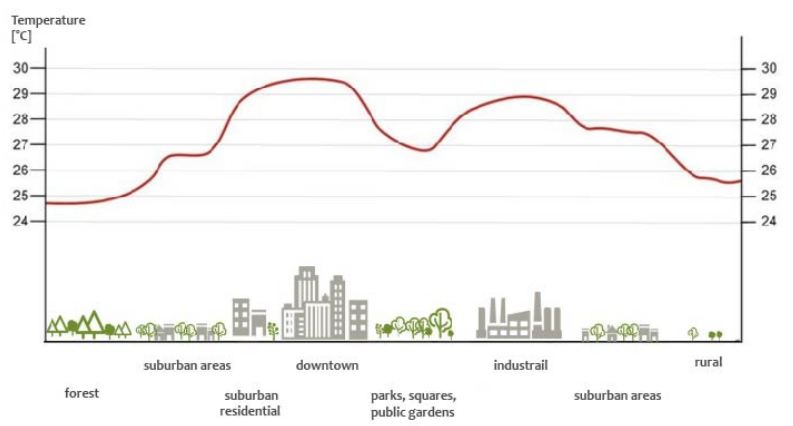

Fig.4. Urban Heat Island (UHI). Source: IETU

The rise of the urban heat island is due to [3]:

- reduced albedo variety of artificial surfaces in the city and the geometry of the city,

- the revised structure of long-term radiation (heat) in built-up areas,

- a small share of natural surface plant,

- human activity,

- the greenhouse effect accompanying the city.

In urban areas are generally not available detailed meteorological data for the determination of the spatial distribution of urban heat island (UHI). Most measurements are performed on representative synoptic stations, located in open areas, in some distance from the city centre and without data from the representative station in the surrounding areas. Therefore the satellite images of surface temperature of the difference land use in the town can be an alternative method for determining of the spatial distribution of the UHI. This method have been used in many urban areas in the world $[1,2,7]$ and in Poland $[3,4,5,6]$.

The UHI is most effected on human quality of life during summer time, our investigations were concerned intensity UHI during summer period.

\section{Methodology}

The current methods for determination of UHI are used both with the standard station meteorological, as well as data from a special observation network, mobile measurement or thermal images of air from satellite.

UHI based on the ground measurements is called the atmospheric heat islands, and this evaluated on the basis of satellite images in literature is called as the surface heat island.

At the heart of the designation of a range of urban heat island (UHI) for Upper Silesia Agglomeration cities lies a few conditions. First, due to the vast range of contemporary surround towns, diversity in land use within the UHI that have been adopted will be set on the basis of the temperature field in the city. The point is that modern cities include areas with highly different thermal properties, reflecting the variation in the land use and also the humidity of the substrate. Secondly, the spatial coverage of UHI was established on the basis of the statistical parameters of temperature distribution within the administrative unit. In this case, the point is that within the city, it can be isolated areas in terms of statistics 
differ significantly from the surrounding areas. In addition, due to the diversity of land use structure of cities, as well as the nature of the satellite data, for each city, you can designate a different limit absorption isotherms by defining the range of the UHI.

Third, the urban heat island affect generally residential area. Not every residential (e.g., disperse build - up) creates the conditions for the emergence of the UHI. However, it is in the form of residential building compact or dense, with little land unspoiled area creates conditions for the formation of the urban heat island. The following methodology to designate urban heat islands for the cities of Upper Silesia Agglomeration has been used.

The first step in extracting the heat island in the city is mapping the ground thermal systems based on a series of satellite images. On this basis, the average temperature of the map was obtained of land obtained based on the dozens of satellite images. For localisation of urban heat islands the Landsat (4-5TM, 7 ETM+, 8 OLI) and ASTER satellite images (using the thermal infrared bands - TIRS, resolution of 4-5TM: 120m, 7 ETM+: $60 \mathrm{~m}$, 100m, ASTER: 90m) have been used. These images were cloud free, summer-time from 2006-2016. According to: https://landsat.usgs.gov/using-usgs-landsat-8-product [8], firstly the radiance had to be calculated, then the brightness temperature:

where:

$$
L_{\lambda}=M L Q c a l+A L
$$

$\mathrm{L}_{\lambda}=$ TOA spectral radiance $\left(\right.$ Watts $\left./\left(\mathrm{m}^{2} * \operatorname{srad} * \mu \mathrm{m}\right)\right)$

$\mathrm{ML}=$ Band-specific multiplicative rescaling factor from the metadata file

$\mathrm{AL}=$ Band-specific additive rescaling factor from the metadata file

Qcal $=$ Quantized and calibrated standard product pixel values (DN)

Then, TIRS band data can be converted from spectral radiance to brightness temperature using the thermal constants provided in the metadata file:

$$
T=\frac{K_{2}}{\ln \left(\frac{K_{1}}{L_{\lambda}}+1\right)}
$$

where:

$\mathrm{T}=$ At-satellite brightness temperature $(\mathrm{K})$

$\mathrm{L}_{\lambda}=$ TOA spectral radiance (Watts $/\left(\mathrm{m}^{2} * \operatorname{srad} * \mu \mathrm{m}\right)$

$\mathrm{K}_{1}$ and $\mathrm{K}_{2}=$ Calibration constants for thermal bands of Landsat.

After calculations, the prepared images were layer stacked. Generally these urban heat islands are constant thus layer stacking and averaging can eliminate several atmospheric or surface distortions. Important to mention is that, the calculated images are not surface temperatures, however in case of urban heat island localisation for longer period, these precise surface temperatures are not necessary.

After layer stacking and averaging there were visible the constant heat emitters such as city centres and residential areas with non - or low vegetation, industrial areas, coal wastes dumps without vegetation, roads and relative cold surfaces e.g. forests, vegetated areas, lakes. Also such layer stacking has prepared for Landsat 4-5TM images from approx. 30 year ago and it could be compared with at present ones. It was also noticed that, better to prepare such layer stacking for max. 2-3 years to have more updated data, than 10 years.

The second step was the designation of the isotherms within the city which is the boundary of the maximum range the urban heat island. Above the absorption isotherms are designated according to the following formula: 


$$
T_{U H I}=\left(\frac{T_{M A X i}+T_{M I N i}}{2}\right)-\left(k * S T D_{i}\right)
$$

where:

$\mathrm{T}_{\mathrm{UHI}}$ - temperature of the urban heat island, the minimum kinetic temperature of UHI constituting the maximum extent of the UHI

$\mathrm{T}_{\mathrm{MAX}}$ - maximum kinetic temperature of surface in town ${ }_{i}$

$\mathrm{T}_{\mathrm{MINi}}$ - minimum kinetic temperature of surface in town ${ }_{i}$

$\mathrm{STD}_{\mathrm{i}}$ - standard deviation of mean kinetic temperature in town ${ }_{\mathrm{i}}$

$\mathrm{k}$ - derivative of land use pattern in $\mathrm{a}_{\mathrm{i}}$ town

Parameter $k$ constitutes the percentage of area of all artificial surfaces in a town. This data can be obtained from Corine Land Cower, Urban Atlas or national land use surveys like for instance in Poland there is a database of topographic objects in scale 1:10 000. Parameter $k$ may also be calculated on the basis of normalized difference vegetation index (NDVI) value.

Parameters $T_{M A X i}, T_{M I N i}$ and $S T D_{i}$ are determined on the basis of raster map of the mean surface kinetic temperature.

The first part of the above equation represents middle surface kinetic temperature in the town. Due to the fact that statistical distribution of the surface kinetic temperature in a given town is not symmetric or even bimodal like in case of analysed example (Figure 5) it turn out that mean or median of the surface kinetic temperature overestimate the area of the UHI while middle temperature underestimate the area. It is important to obtain appropriate temperature corresponding to lower temperature boundary of UHI. To low temperature results in encompassing in the UHI green areas, to high - omitting built up areas. This is the reason why the second part of the equation was added.

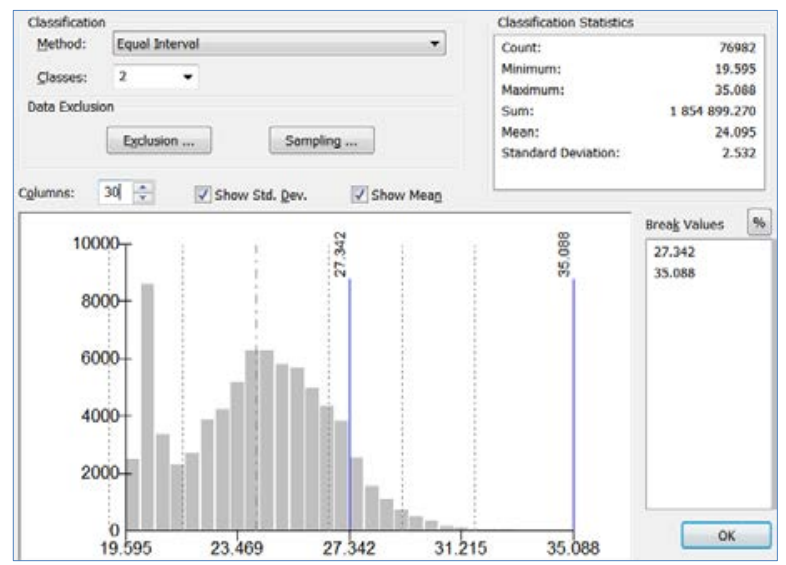

Fig. 5. Histogram of the surface kinetic temperature of the Bytom town

\section{Results}

At the first step the surface heat kinetic temperature had been determined for Upper Silesian Agglomeration as the mean values from the period 1986-2016 which is presented on the Figure 6. This resolution was not proper for detail recognizing the differences of the surface temperatures inside the cities. Only the analyses for particular towns allowed on the determination of changes in surface temperatures during the summer period of different land use areas inside the cities in the analysed period 1986 - 2016. There were chosen three 
representative areas for introducing different heat emitters (Figure 6). In the case of Bytom, where the city center has been densely built up may indicate the occurrence of UHI. Furthermore the shape of these problematic areas has not changed since 1987-1988, rather increased e.g. on the southern part of the city where new coal waste dumps (with bare surfaces) were deposited. Another problematic areas are introduced by Katowice where a new heat emitter has constructed (shopping centres) in comparison to 1987-1988 (see Figure 6, Katowice, middle part of the image). The applied roof material for such newer buildings should be reconsidered as they serve as potential heat source. Similar problematic areas can be described by Dąbrowa Górnicza, where the industrial facilities occurring as a large heat source together with newer buildings with same problems as previously mentioned by Katowice (roofs). As Figure 6 indicating the extended deep lakes (Dąbrowa Górnicza) or construction new parks, increased number of trees in city center can serve as a cooling feature.

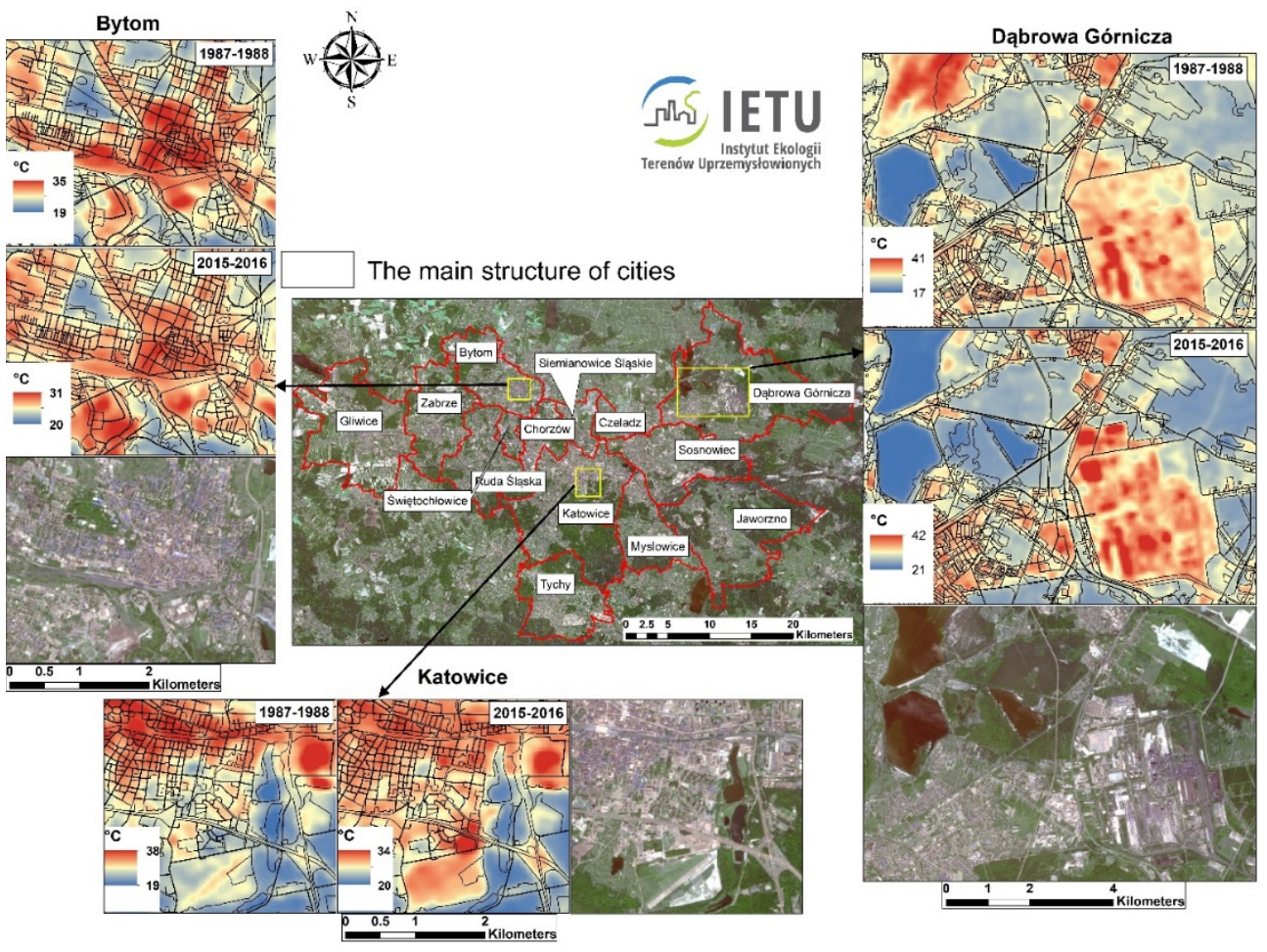

Fig. 6. Chosen three representative problematic areas in the Upper Silesian Agglomeration.

The examples outlined above, indicate the ability to monitor changes to the spatial distribution of surface temperatures within the city due to its development and the identification of the major emitters of the heat into the environment, affecting the inhabitants quality of life.

The boundary of the heat island inside the town due to equation 2 omit the areas with the surface temperature below the mean value. The value of this isotherm depends on the value of $k$ factor used as it is presented on the example of Bytom city.

Extent of the urban heat island presented on Figure 7. is the case applied in Municipal Plan for Adaptation (MPA) project. The lowest temperature of the UHI was determined as middle kinetic temperature minus standard deviation of the kinetic temperature observed in 
a given city. In case of the Bytom city thus obtained $T_{U H I}$ equals $24.9^{\circ} \mathrm{C}$. The area defined by isoline of $T_{U H I}$ is 3145.41 ha, what constitutes $45.4 \%$ of the whole city area. The residential area covers area of 1042.07 ha what constitutes $15.03 \%$ of the city area.

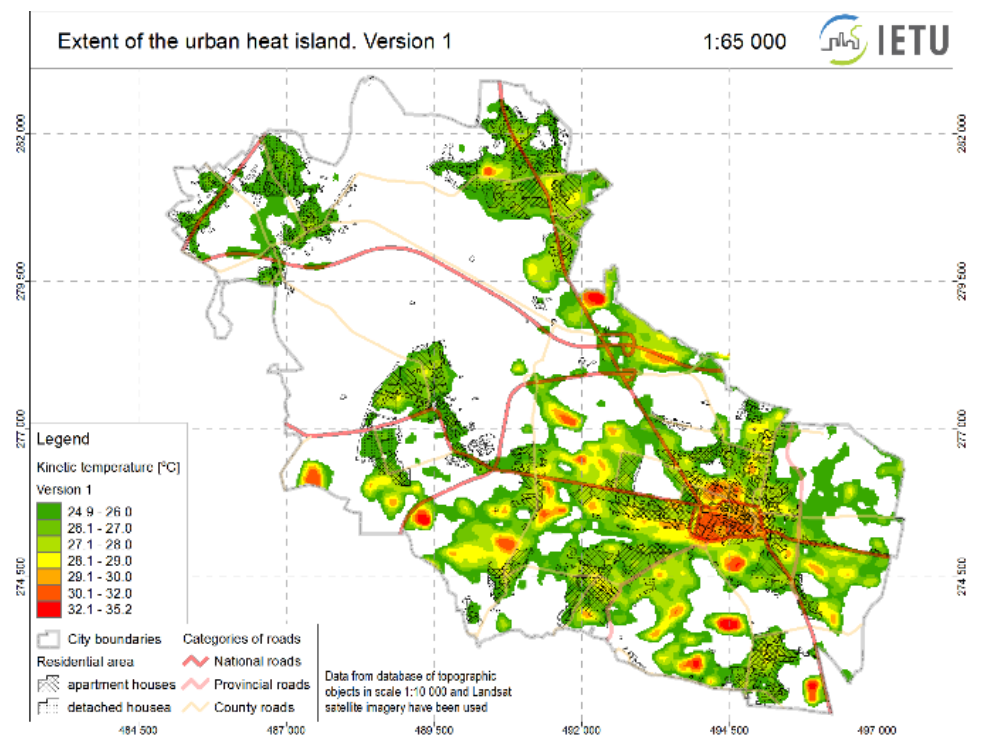

Fig. 7. Extent of the urban heat island of Bytom determined by use of $k=1$

Extent of the urban heat island presented on Figure 8. is the case when the standard deviation was multiplied by half of percentege of artifical areas (see equation 2). In case of the Bytom city thus obtained $T_{U H I}$ equals $26.86^{\circ} \mathrm{C}$. The area defined by isoline of $T_{U H I}$ is $1237.23 \mathrm{ha}$, what constitutes $17.8 \%$ of the whole city area.

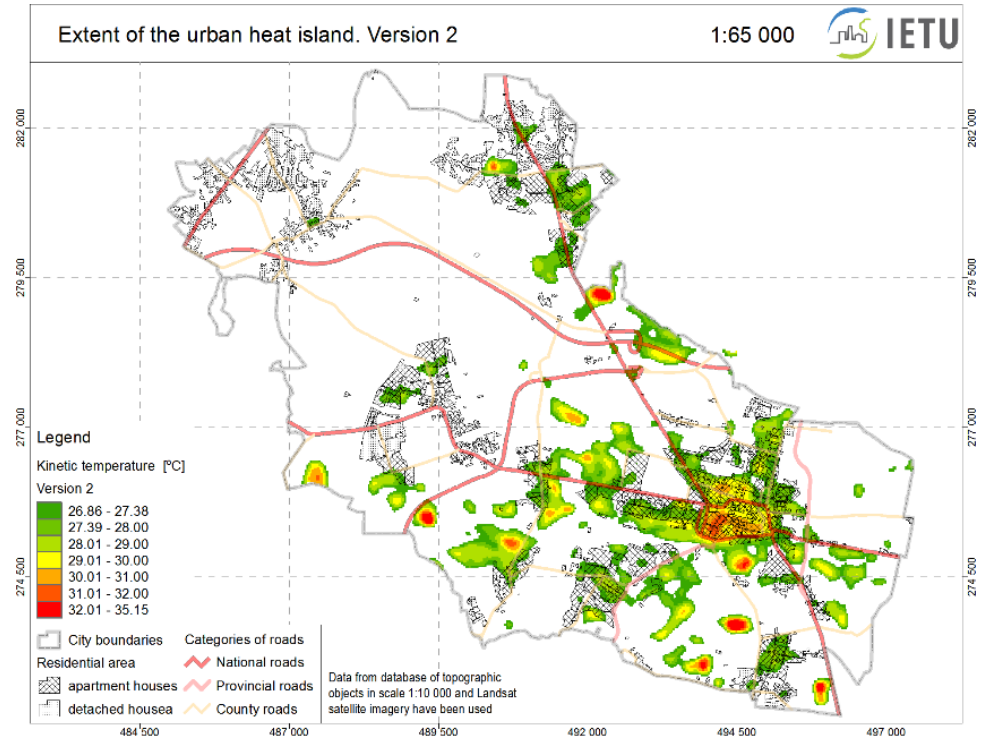


Fig. 8. Extent of the urban heat island of Bytom determined by use of $k=1 / 2$ percentage of artificial area in town

The correctness of the application of the $k$ factor value requires further research, however, it should be noted that the use of $k=1 / 2$ percentage of artificial area in town allows to pinpoint most vulnerable areas to the adverse effects of UHI, where adoption activities should be undertaken immediately.

\section{Conclusions}

Examples of the use of satellite images technique described above for determine the kinetic surface temperature distribution in the cities area, with different way of development, seems to be the only possible method in the analysis of the urban heat island (UHI) at the stage of preparation of urban plans for adapting to climate change (MPA) in the different size of cities. This method allows to monitor changes in the occurrence of critical areas in the city over the past 30 years, resulting from the development of the city. These critical areas emit the heat into the atmosphere and affecting the temperature of the ambient air, as well affecting the quality of human life. In particular, vulnerable groups (children, persons age 65 and $>$ cardiovascular diseases and respiratory diseases). This method also allows to determine the isotherm range the urban heat island, limited to the most vulnerable to the adverse effects of surface heat emitters on the comfort of life. Although the using $k=1 / 2$ percentage of artificial area in town allows to pinpoint most vulnerable areas to the adverse effects of UHI, where adoption activities should be undertaken immediately, however the correctness of the application of the $k$ factor value requires further. The use of satellite imagery for this type of analysis is much cheaper than ground-based measurements of the air temperature in a network of dozens of measurement points in the city and in surrounding areas for at least a year.

\section{References}

1. B. Dousset, F. Gourmelon, E. Mauri. Urban Remote Sensing Joint Event, Application of satellite remote sensing for urban risk analysis: a case study of the 2003 extreme heat wave in Paris, (Telecom Paris, 2007)

2. L. Liu, Y. Zhang, Remote Sens., Urban Heat Island Analysis Using the Landsat TM Data and ASTER Data: A Case Study in Hong Kong, 3, 1535-1552 (2011)

3. K. Błażejczyk, M. Kuchcik, P. Milewski, W. Dudek, B. Kręcisz, A. Błażejczyk, J. Szmyd, B. Degórska, C. Pałczyński, Miejska wyspa ciepła w Warszawie. (Publishing house Sedno, 2014)

4. J. Walawender, M. Hajto, P. Iwaniuk, Rocz. Geomat., Zastosowanie algorytmu „pojedynczego okna” do opracowania map temperatury powierzchni ziemi na podstawie danych satelitarnych LANDSAT, 9, 4, 139-150 (2011)

5. J. Walawender, M. Hajto, P. Iwaniuk, Proc. IEEE IGARSS, A new ArcGIS toolset for automated mapping of land surface temperature with the use of LANDSAT satellite data, 4371-4374, (2012)

6. J. Walawender, M. Szymanowski, M. J. Hajto, A. Bokwa, Pure and Applied Geophysics, Land Surface Temperature Patterns in the Urban Agglomeration of Krakow (Poland) Derived from Landsat-7/ETM+ Data, 913-940 (2014)

7. EPA, Reducing Urban Heat Islands: Compendium of Strategies Urban Heat Island Basics, (2014)

8. https://landsat.usgs.gov/using-usgs-landsat-8-product 